\section{A SMART TOOTHBRUSH WITH DRAMATIC BATHROOM APPEAL}

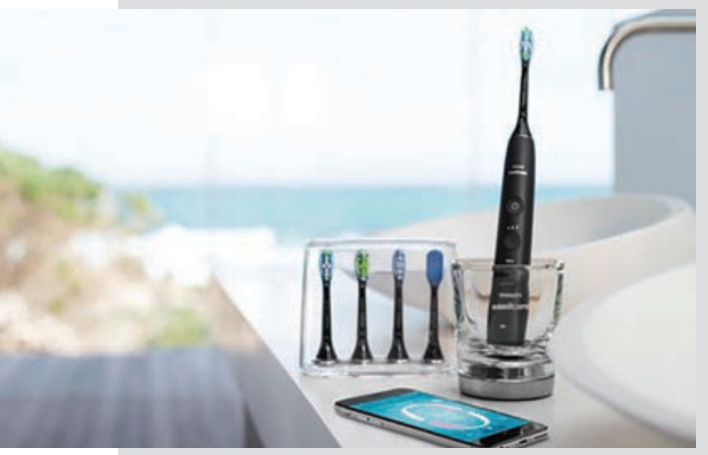

Philips Sonicare has revealed a new flagship innovation - the DiamondClean Smart - dubbed the world's most intelligent toothbrush. The new brush uses unique connected technology to inspire and motivate patients to take better care of their oral health. It delivers exceptional oral care results by harnessing built-in smart sensor technology in both the toothbrush and brush heads and personalised coaching within the platform to help improve patients' brushing technique and ultimately achieve a healthier mouth. The new brush seamlessly syncs with the Philips Sonicare app, giving users real time data,

\title{
STRONG AND SUPERIOR EXAMINATION GLOVES
}

Demonstrate your conviction and commitment to safe dentistry by selecting strong and superior examination gloves from Unigloves.

As an expert in the field of single-use gloves, Unigloves has developed the Vitality Range of premium latex and nitrile gloves specifically for the dental sector:

- Vitality Latex - $100 \%$ latex, powder free, single use gloves with a naturally moisturising lanolin and vitamin $\mathrm{E}$ coating to protect and nourish the skin

- Vitality Mint Latex - 100\% latex, powder free, single use gloves with natural moisturisers and scented with citrus and peppermint for a pleasant taste
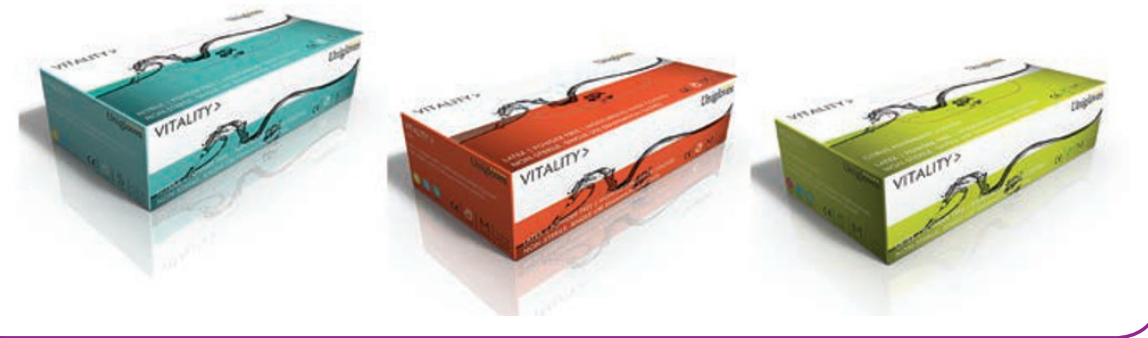
single use gloves with a na of lanolin and vitamin $\mathrm{E}$.

Every pair features double-chlorinated beaded cuffs to make them easy to use and a micro-roughened surface for excellent grip and dexterity.

The Vitality Range is fully compliant with all relevant UK regulations and with the purpose of delivering safety through quality; Unigloves ensure that their gloves are produced to the very highest standards with precision and care.

To make a positive statement about hygiene and infection control at your practice, contact Unigloves today. www.unigloves.co.uk feedback and guidance to empower them to proactively manage and improve their oral health.

DiamondClean Smart is smart in more ways than one - it also has dramatic bathroom appeal with its matt black handle, black brush head and charge-in-a-glass technology. The brush can also be charged using a computer USB to top up whilst travelling.

Philips interproximal cleaning device, the AirFloss, has been upgraded with a new Charge and Fill docking station. The new add-on allows users to automatically refill their AirFloss with water or mouthwash about juggling bottles or spills. The compact docking station filler holds enough liquid for two weeks' worth of cleaning, without the faff. At the end of the one minute, full mouth clean the AirFloss can then re-dock to keep the device charged and ready to use (although it holds two weeks charge for people on the go).

For further information on the latest Philips innovations visit www.philips-tsp. co.uk or call 08000567222. in less than ten seconds without worrying

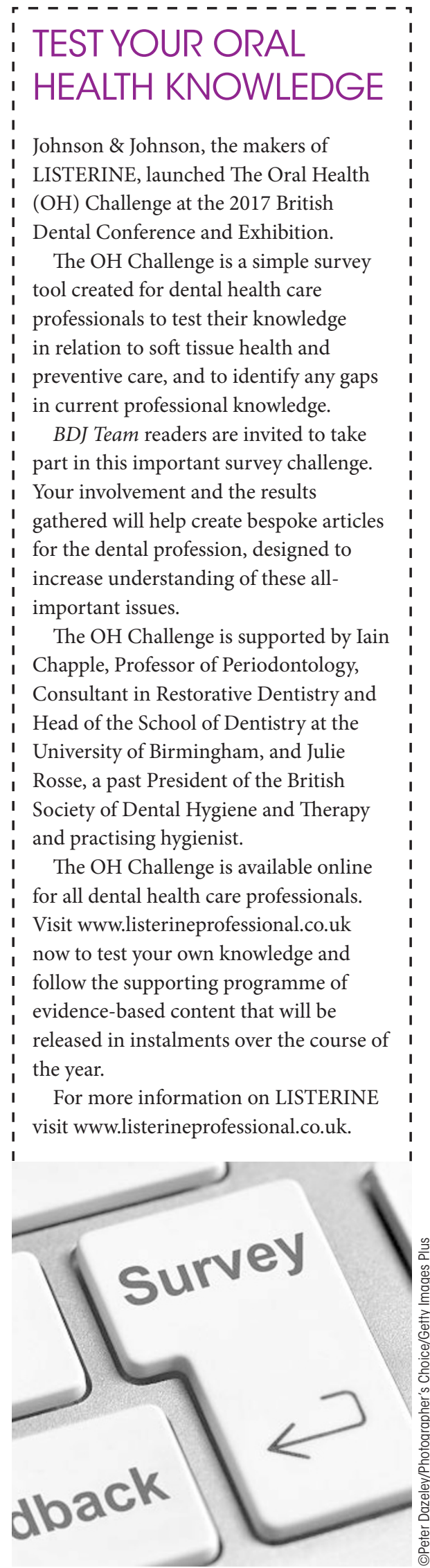 products or services direct to the dental industry in BDJ Team, call Andy May on 02078434785 or emaila.may@nature.com

you would like to promote your 